\title{
Effects of high dose prednisolone on optic nerve head blood flow in patients with acute optic neuritis
}

\author{
Hemma Resch1,2, Günther Weigert ${ }^{1,2}$, Gerhard Garhöfer ${ }^{1,2}$, Karl Kircher², \\ Guido T Dorner ${ }^{2}$, Andreas Reitner ${ }^{2}$ and Leopold Schmetterer*1,3
}

\author{
Address: ${ }^{1}$ Department of Clinical Pharmacology, Medical University of Vienna, Austria, ${ }^{2}$ Department of Ophthalmology, Medical University of \\ Vienna, Austria and ${ }^{3}$ Center of Biomedical Engineering, Medical University of Vienna, Austria \\ Email: Leopold Schmetterer* - leopold.schmetterer@meduniwien.ac.at \\ * Corresponding author
}

from 13th Scientific Symposium of the Austrian Pharmacological Society (APHAR). Joint Meeting with the Austrian Society of Toxicology (ASTOX) and the Hungarian Society for Experimental and Clinical Pharmacology (MFT)

Vienna, Austria. 22-24 November 2007

Published: 14 November 2007

BMC Pharmacology 2007, 7(Suppl 2):A30 doi:I0.I I86/I47I-22 I0-7-S2-A30

This abstract is available from: http://www.biomedcentral.com/I47I-22 I0/7/S2/A30

(C) 2007 Resch et al; licensee BioMed Central Ltd.

\section{Purpose}

In the present study patients with optic neuritis were treated with high dose prednisolone. Little information is available about the effects of this treatment on ocular blood flow. We set out to investigate the effects of high dose prednisolone on optic nerve head blood flow in patients with acute optic neuritis.

\section{Methods}

Nine patients with acute optic neuritis were included in the study. One gram of prednisolone was infused intravenously over 30 minutes on three consecutive days. On each study day optic nerve head blood flow was measured using laser Doppler flowmetry. The ocular hemodynamic measurements were performed on the contralateral eye of the patients with optic neuritis before and immediately after cessation of the infusion. Intraocular pressure and systemic blood pressure was measured before and after the infusion on each study day. Data was analyzed using a 3-2 repeated measures ANOVA model.

\section{Results}

Prednisolone increased optic nerve head blood flow in the patients under study $(\mathrm{p}<0.05)$. No significant change in mean arterial pressure $(\mathrm{p}=0.14)$ or intraocular pressure $(\mathrm{p}=0.91)$ could be detected in the patients treated with high dose prednisolone.

\section{Conclusion}

High dose prednisolone showed a small but significant increase in optic nerve head blood flow. Further studies are required to study whether this effect contributes to the therapeutic efficacy of cortisone in patients with optic neuritis. 